\title{
Comparative Analysis of Effect of Density, Insertion Angle and Reinsertion on Pull-Out Strength of Single and Two Pedicle Screw Constructs Using Synthetic Bone Model
}

\author{
Venkatesh Krishnan ${ }^{1}$, Vicky Varghese ${ }^{2}$, Gurunathan Saravana Kumar ${ }^{3}$ \\ ${ }^{1}$ Spinal Disorders Surgery Unit, Department of Orthopedics, Christian Medical College, Vellore, India \\ ${ }^{2}$ Department of Biotechnology, Indian Institute of Technology Madras, Chennai, India \\ ${ }^{3}$ Department of Engineering Design, Indian Institute of Technology Madras, Chennai, India
}

Study Design: Biomechanical study.

Purpose: To determine the effect of density, insertion angle and reinsertion on pull-out strength of pedicle screw in single and two screw-rod configurations.

Overview of Literature: Pedicle screw pull-out studies have involved single screw construct, whereas two screws and rod constructs are always used in spine fusions. Extrapolation of results using the single screw construct may lead to using expensive implants or increasing the fusion levels specifically in osteoporotic bones.

Methods: Single screw and two screw pull-out strength tests were carried out according to American Society for Testing and Materials F 543-07 on foam models to test the effect of density, insertion angle and reinsertion using poly axial pedicle screws.

Results: Bone density was the most significant factor deciding the pull-out strength in both single and two screw constructs. The difference in pull-out strength between single screw and two screw configurations in extremely osteoporotic bone model $\left(80 \mathrm{~kg} / \mathrm{m}^{3}\right)$ was $78 \%$, whereas in the normal bone model it was $48 \%$. Axial pull-out value was highest for the single screw configuration; in the two screw configuration the highest pull-out strength was at $10^{\circ}-15^{\circ}$. There was an $18 \%$ reduction in pull-out strength due to reinsertion in single screw configuration. The reinsertion effect was insignificant in the two screw configuration.

Conclusions: A significant difference in response of various factors on holding power of pedicle screw between single and two-screw configurations is evident. The percentage increase in pull-out strength between single and two screw constructs is higher for osteoporotic bone when compared to normal bone. Reinsertion has no significant effect on pull-out strength in the two screw rod configuration.

Keywords: Pedicle screw; Pullout test; Osteoporosis; Spine fusion; Screw fixation

\section{Introduction}

Despite advancements in pedicle screw instrumentation, failures including screw breakage and loosening due to fatigue loading and bending continue to be reported [1]. The incidence of screw breakage ranges between $2.6 \%$

Received Sep 26, 2015; Revised Oct 27, 2015; Accepted Oct 27, 2015

Corresponding author: Venkatesh Krishnan

Spinal Disorder Sugery Unit, Department of Orthopaedics, Christian Medical College,

Vellore, Tamil Nadu 632004, India

Tel: +91-416-2282731, Fax:+91-416-2232103, E-mail: venketeshortho1@cmcvellore.ac.in 
and $60 \%$, and often occurs around the thread-shank region. This is commonly due to nonunion, whereas the incidence of screw loosening usually due to osteoporosis ranges from $0.6 \%$ to $11 \%$ [2-4]. These failures and insufficient fixation necessitate subsequent surgery [5].

The principal obstacle encountered with surgical intervention in osteoporotic patients is achieving optimal pedicle screw fixation within a bone of lower density, as the incidences of screw loosening and pull-out remain high $[6,7]$. Currently, osteoporosis is not a contraindication for fusion surgery and the same type of instrumentation is used for both the normal and osteoporotic condition with some modifications. Spinal fixation failure due to osteoporosis or other metabolic bone diseases can require replacement of pedicle screws or extension of fusion [810]. Revisions are associated with significant surgical risks and further revisions might have to be performed [11]. Two common trajectories exist for the insertion of pedicle screws: the straightforward trajectory $\left(0^{\circ}\right.$ to $10^{\circ}$ both in the medial and caudal directions) and the anatomic trajectory $\left(0^{\circ}\right.$ to $10^{\circ}$ medial and $22^{\circ}$ cephalocaudal) [12]. These wide ranges of insertion angle can lead to varying results for pedicle screw instrumentation.

The pull-out strength of pedicle screws is an important index used by manufacturers and surgeons to know the holding power of pedicle screw and objectively demonstrate their resistance to axial load [9]. Pull-out strength is dependent on several factors including screw design, insertion technique, bone quality and size of the pedicle [13-15]. Studies to date are predominantly based on single screw pull-out strength, which may not be the actual representation of screw failure in vivo.

The purpose of the present study is to compare the effect of various factors on pull-out strength in single screw and two screw rod configurations. The pull-out studies were carried out in synthetic bone models of differing densities of cancellous bone representing normal and osteoporotic bone using conventional single screw pullout and the two screw instrumentation that mimicked the in vivo configuration. This study considered the effects of bone density, screw insertion angle and reinsertion on pull-out force in the two test configurations.

\section{Materials and Methods}

\section{Synthetic bone model}

Rigid polyurethane foams are widely used as a substitute for cadaveric spinal bone because of their consistent and homogeneous structural properties [16]. In the current study, rigid polyurethane foam representing extremely osteoporotic to normal bone was used. The different grades and their corresponding equivalence in densities were: Grade $5\left(80 \mathrm{~kg} / \mathrm{m}^{3}\right)$ representing extremely osteoporotic bone density, Grade $10\left(160 \mathrm{~kg} / \mathrm{m}^{3}\right)$ representing osteoporotic, Grade $15\left(240 \mathrm{~kg} / \mathrm{m}^{3}\right)$ representing normal bone density and Grade $20\left(300 \mathrm{~kg} / \mathrm{m}^{3}\right)$ representing more than normal bone density. These bone densities were regulated and standardized according to the American Society of Testing Materials ASTM F-1839 protocol [15,17]. A block of dimension $120 \mathrm{~mm} \times 60 \mathrm{~mm} \times 40 \mathrm{~mm}$ was sawn from blank for each test.

\section{Pedicle screw instrumentation}

CE approved, medical grade titanium alloy, polyaxial pedicle screws GESCO (General Surgical Co., Chennai, Tamil Nadu, India) with a diameter of 6 or $7 \mathrm{~mm}$, and length of $40 \mathrm{~mm}$ (Fig. 1) were used. The dimensions of the pedicle

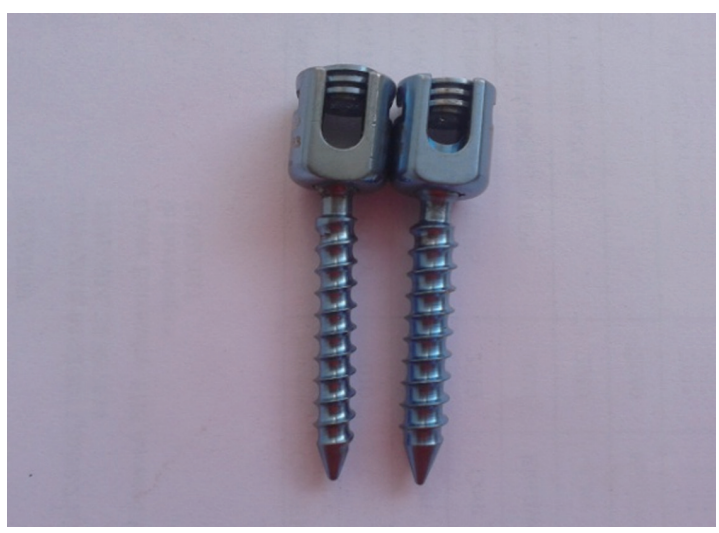

Fig. 1. GESCO screw.

Table 1. Pedicle screw dimensions (all values in $\mathrm{mm}$ )

\begin{tabular}{lcccc} 
Screw Type & Major diameter, $D_{\text {major }}$ & Minor diameter, $D_{\text {minor }}$ & Thread length, $L$ & Thread pitch, $p$ \\
$\emptyset 6 \mathrm{~mm} \times 40 \mathrm{~mm}$ & 6 & 4.2 & 30 & 3 \\
$\varnothing 7 \mathrm{~mm} \times 40 \mathrm{~mm}$ & 7 & 4.9 & 30 & 3 \\
\hline
\end{tabular}



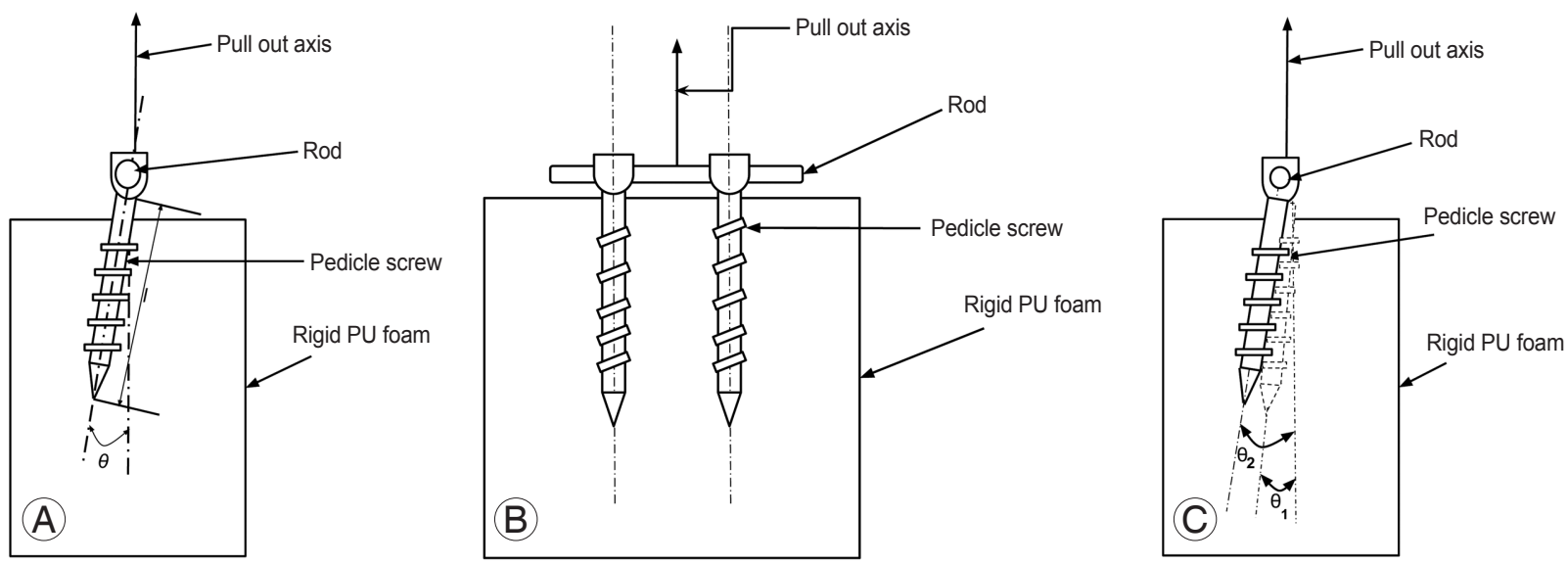

Fig. 2. Schematic representation of pull-out study. (A) Single screw configuration. (B) Two screw and rod configuration. (C) Side view of two screw and rod configuration. PU, polyurethane foam.

Table 2. Factors and their levels for pull out strength studies in single screw configuration

\begin{tabular}{llrrrr}
\multicolumn{1}{c}{ S. No } & \multicolumn{3}{c}{ Levels } \\
\hline 1 & Density, $\rho\left(\mathrm{kg} / \mathrm{m}^{3}\right)$ & 80 & 160 & 240 & 300 \\
2 & Insertion angle, $\theta\left(^{\circ}\right)$ & 0 & 10 & 20 & 30 \\
\hline 3 & Reinsertion & 0 & 1 & - & - \\
\hline
\end{tabular}

Table 3. Factors and their levels for pull out strength studies in two screw and rod configuration

\begin{tabular}{llcccc}
\multicolumn{1}{c}{ Factor } & \multicolumn{3}{c}{ Levels } \\
\hline 1 & Density, $\rho\left(\mathrm{kg} / \mathrm{m}^{3}\right)$ & 80 & 160 & 240 & 300 \\
2 & Two screw Insertion angles, $\theta\left(^{\circ}\right)$ & $5-10$ & $10-15$ & $15-20$ & $20-25$ \\
\hline 3 & Reinsertion & 0 & 1 & - & - \\
\hline
\end{tabular}

screw are shown in Table 1. A $5.5 \mathrm{~mm}$ diameter high tensile stainless steel rod was used to connect the pedicle screws.

Pilot holes were drilled along the longitudinal axis of the pedicle screw and at different angles to the foam using a $4 \mathrm{~mm}$ diameter drill bit. Holes were drilled $25 \mathrm{~mm}$ away from each other so as to avoid an interaction effect and also to be representative of the average distance between the lumbar spine pedicles. Fig. 2A depicts the schematic representation of single screw pull-out study configuration. To study pull-out strength in the two screw and rod configuration, the screws were inserted at different angles and connected with a rod as shown in Fig. 2B and C.

\section{Experiment design}

Full factorial experiment [18] was used to study the effects of bone density, screw insertion angle and reinser- tion on pull-out strength in single screw and two screw and rod configurations. The density ranges were chosen to represent osteoporotic to more than normal bone density. The insertion angles were chosen based on the anatomy of pedicle angle for the L1-L5 region. The angle of the pedicle in lumbar vertebrae increases incrementally by $5^{\circ}$ at each level [19]. Reinsertion represents the scenario of pedicle screw revision surgery when there is an implant failure. During such a scenario the construct is instrumented with a pedicle screw of higher diameter. The different factors and their levels used are shown in Tables 2 and 3. In all 32 pull-out tests for each single and two screw constructs, three repetitions were done.

\section{Pull-out strength test}

Pull-out tests on the foam with the inserted screws were done using a BiSS Nano-25 universal testing machine. A 
$5.5 \mathrm{~mm}$ diameter tensile steel rod was fixed to the pedicle screw using a set screw mimicking the actual configuration of the pedicle screw. This was mounted on a test jig with a variable axis frame used to align the pull-out axis to the screw (Fig. 3). A tensile load of $5 \mathrm{~mm} / \mathrm{min}$ was applied to the test specimen until the screw released from the test block. The procedures were controlled under the provision of ASTM: F543-07 protocol [20]. Load and displacement values were recorded and the maximum load generated during screw pull-out was defined as the pullout strength of the screw.

\section{Statistical analyses}

Statistical comparisons were made using MINITAB Release

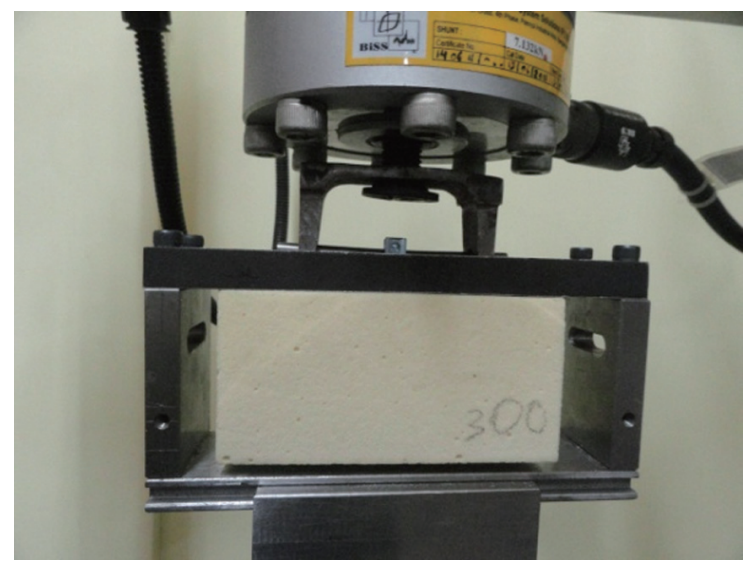

Fig. 3. Setup for pull-out strength study.

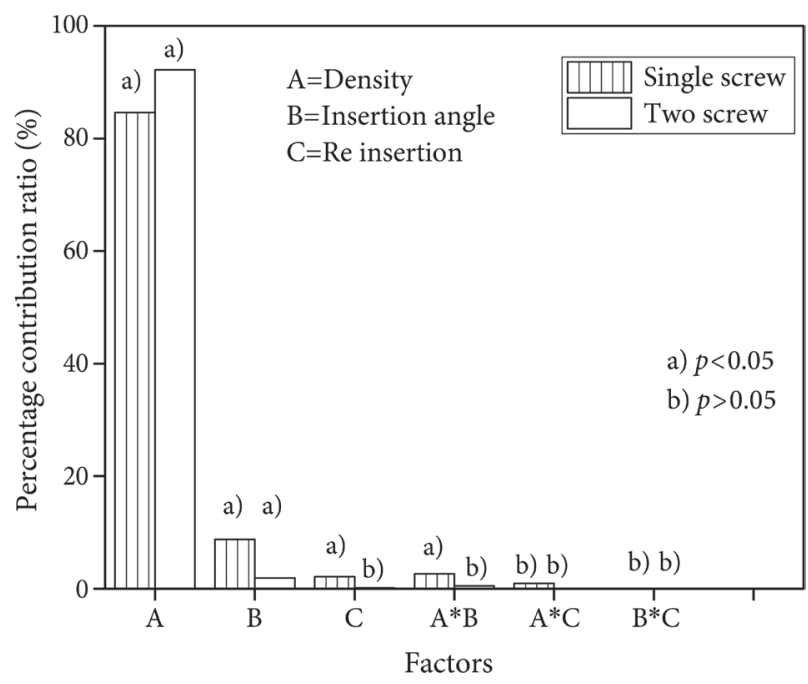

Fig. 4. Percentage contribution ratio of factors effecting pull-out strength.
16 Statistical Software (Minitab Inc., State College, PA, USA). Analysis of variance (ANOVA) and Tukey's Honestly Significant Difference multiple comparison tests was used. A $p$-value $<0.05$ was considered statistically significant [18].

\section{Results}

The results of pull-out studies were analyzed for factor effect using ANOVA. Fig. 4 describes the strength of factor and their interaction effect on the pull-out values in single and two screw constructs. In the single screw configuration, density, insertion angle and reinsertion had significant effects on pull-out strength of pedicle screw (all $p<0.05$ ). The interaction effects of density and insertion angle were also significant. Density had the highest contribution to the pull-out strength in the single screw configuration at $85 \%$, whereas insertion angle contributed to $9 \%$ of pull-out strength. Reinsertion contributed $2 \%$ and the remainder was contributed by interaction effects.

In the two screw and rod configuration, density and insertion angle had significant effects on pull-out strength of pedicle screw (both $p<0.05$ ). Reinsertion and all interaction effects had no significant effect on pull-out strength of pedicle screw (all $p>0.05$ ). In the two screw configuration, density had the highest contribution at $92 \%$ followed by insertion angle at $2 \%$. Reinsertion and other interaction effects each contributed $<1 \%$.

\section{Effect of bone density on pull-out strength}

The pull-out strength increased with increasing density in both single screw and two screw and a rod configurations (Fig. 5). The pull-out strength was highest in foam representing more than normal bone density $\left(300 \mathrm{~kg} / \mathrm{m}^{3}\right)$ in both the single screw $(1.107 \pm 0.23 \mathrm{kN})$ and two screw configuration $(1.935 \pm 0.20 \mathrm{kN})$. There was a $78 \%$ increase in pull-out strength between single screw $(0.213 \pm 0.04$ $\mathrm{kN})$ and two screw configuration $(0.3798 \pm 0.03 \mathrm{kN})$ in extremely osteoporotic bone model $\left(80 \mathrm{~kg} / \mathrm{m}^{3}\right)$, whereas in case of normal bone model $\left(240 \mathrm{~kg} / \mathrm{m}^{3}\right)$ the increase was only $42 \%$ in the two screw configuration $(1.39 \pm 0.17 \mathrm{kN})$ over the single screw configuration $(0.973 \pm 0.16 \mathrm{kN})$. In the osteoporotic bone model $\left(160 \mathrm{~kg} / \mathrm{m}^{3}\right)$ an increase of $67 \%$ in pull-out strength was evident between the single $(0.5015 \pm 0.17 \mathrm{kN})$ and two screw configuration $(0.841 \pm 0.20 \mathrm{kN})$. 


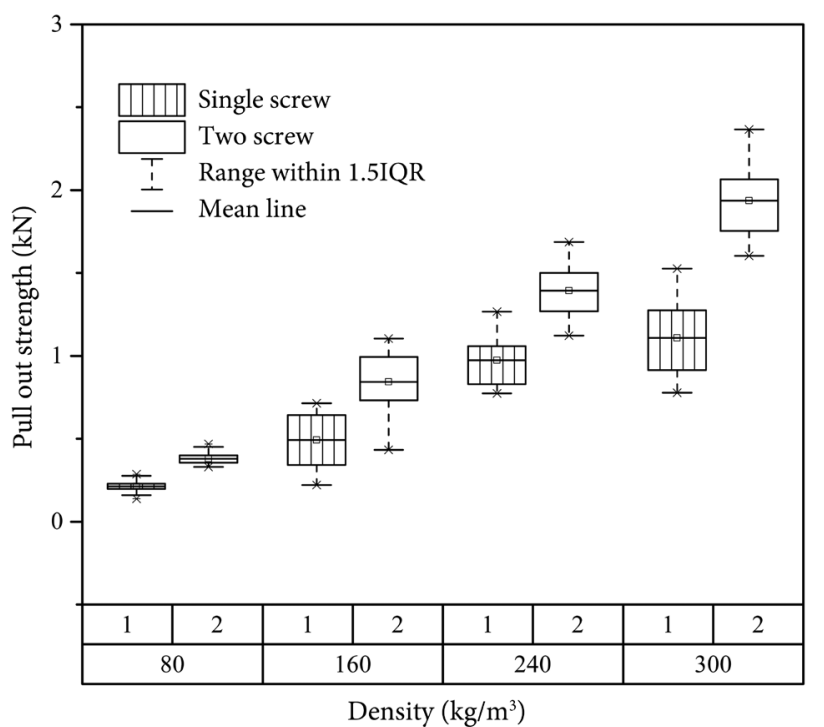

Fig. 5. Effect of density on pull-out strength of pedicle screw. IOR, interquartile range.

\section{Effect of insertion angle on pull-out strength}

The effect of insertion angle on pull-out strength of pedicle screw is presented in Fig. 6A. In the single screw configuration, the pull-out strength was highest in axial pull-out condition and decreased with increasing screw insertion angle. The pull-out value decreased by $52 \%$ between insertion angles of $0^{\circ}(0.816 \pm 0.42 \mathrm{kN})$ and $30^{\circ}(0.536 \pm 0.32$ $\mathrm{kN})$. In the two screw-rod configuration, the pull-out strength was maximum for insertion angles of $10^{\circ}-15^{\circ}$ $(1.242 \pm 0.68 \mathrm{kN})$. The pull-out strength decreased by $17 \%$ between insertion angle configurations of $5^{\circ}-10^{\circ}$ and $20^{\circ}-25^{\circ}$. The difference between pull-out force for single screw at $0^{\circ}(0.816 \pm 0.42 \mathrm{kN})$ and two screw-rod configuration at $5^{\circ}-10^{\circ}(1.184 \pm 0.60 \mathrm{kN})$ was $45 \%$. This difference was highest $(88 \%)$ between single screw at $30^{\circ}(0.536 \pm 0.32$ $\mathrm{kN})$ and two screw at $20^{\circ}-25^{\circ}(1.008 \pm 0.50 \mathrm{kN})$.

Since a significant interaction effect was observed between density and insertion angle in case of single screw configuration, the same is plotted in Fig. 6B. The pullout strength decreases with increase in angle in extremely osteoporotic and normal bone model. In osteoporotic and more than normal bone model the pull-out strength is highest for $10^{\circ}$ configuration.

\section{Effect of reinsertion on pull-out strength}

The effect of reinsertion on pull-out strength of pedicle screw is shown in Fig. 7. A reduction in holding power
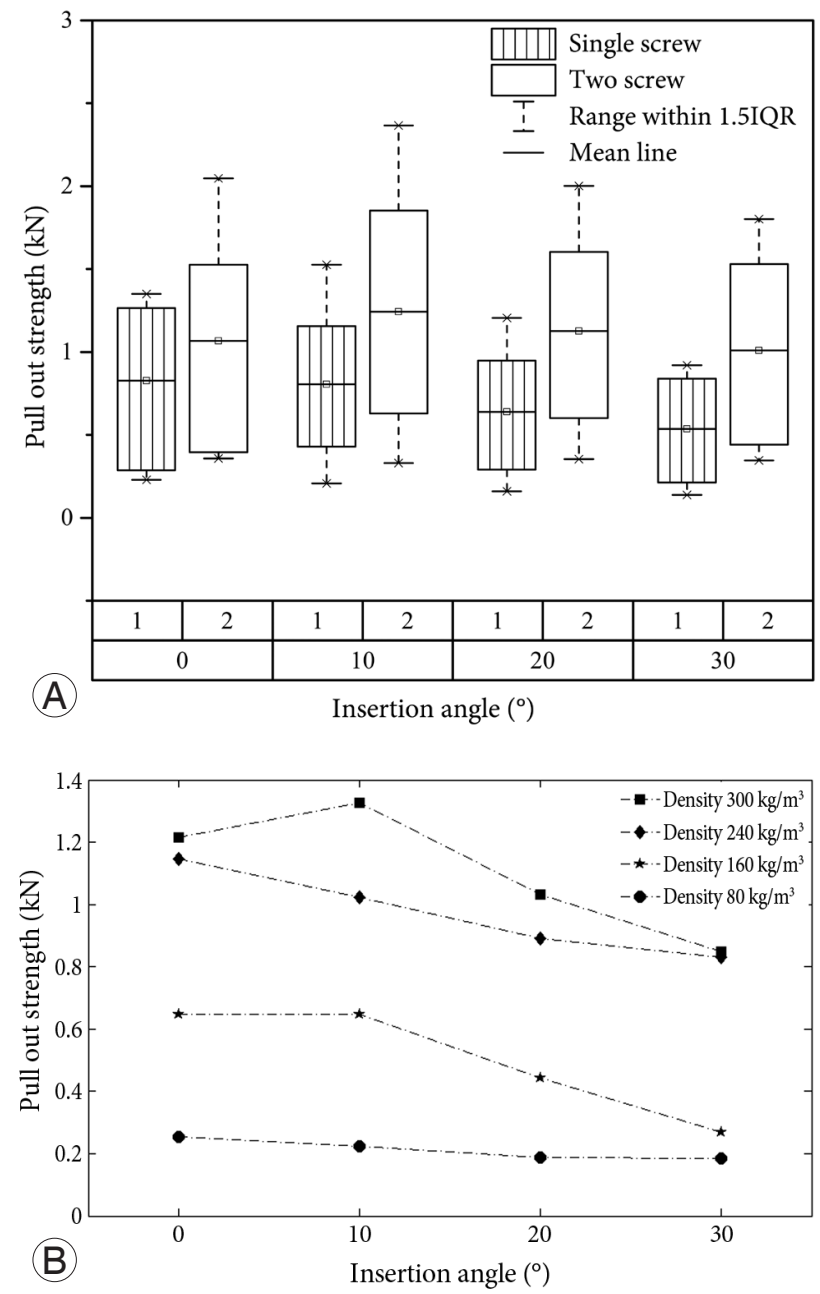

Fig. 6. Effect of insertion angle. (A) Effect of angle on pull-out strength of pedicle screw. (B) Effect of angle on pull-out strength of single screw in different bone densities. IQR, interquartile range.

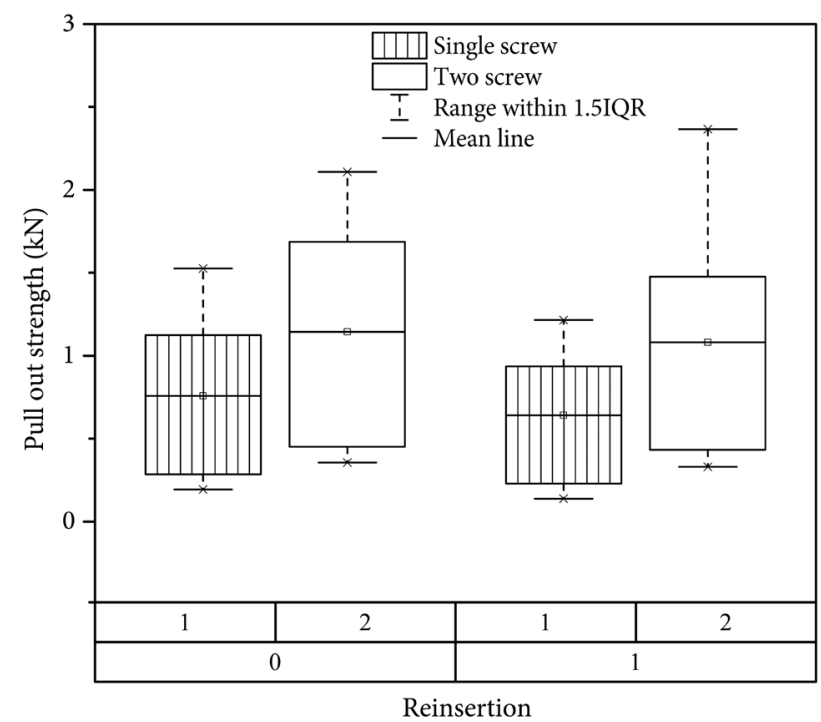

Fig. 7. Effect of reinsertion on pull-out strength of pedicle screw. IQR, interquartile range. 
was evident after reinsertion with a higher diameter screw in both the single and two screw configurations. There was an $18 \%$ decrease in pull-out strength due to reinsertion $(0.641 \pm 0.35 \mathrm{kN})$ in single screw pull-out. In the two screw and rod configuration, there is a decrease of $5 \%$ in pull-out strength due to reinsertion $(1.11 \pm 0.58 \mathrm{kN})$ with a higher diameter screw.

\section{Discussion}

Pedicle screw fixation is considered the gold standard for lumbar spine fusion surgeries. It improves the rate of fusion, avoids external immobilization and aids in early recovery. Osteoporosis and revision surgeries remain a challenge for fusion with pedicle screw systems. Traditional single screw pull-out strength studies in healthy and osteoporotic spine have demonstrated a significant effect of density on holding power of pedicle screw $[15,16]$. Patel et al. [21] reported that the effect of screw insertion angle on pull-out differed between an osteoporotic and normal bone. Research focusing on the effects of various factors like bone density, screw type and screw insertion angle on the stability of screws have often involved single screw pull-out studies $[1,5,8,9]$. But, in vivo a two screw construct is typically used. Extrapolation of single screw pull-out studies could underestimate the efficacy of the actual two screw and rod construct during surgery. Clinically this could result in the use of expensive pedicle screw systems or extension of fusion construct, which has economic and functional consequences.

This study investigated the effect of several factors affecting screw pull-out in single and two screw constructs by systematically varying bone density, screw insertion angle and the effect of reinsertion. The present study is first to differentiate the effect of these important factors on pull-out of the single screw construct, which is typically used in screw pull-out tests, and the two screw construct that is similar to the configuration of an in vivo construct.

The present study was done using polyurethane foam models representing different bone densities. Though studies based on rigid polyurethane foam have certain limitations, which cannot mimic the cadaveric model, Kim et al. [15] demonstrated that the axial pull-out studies in polyurethane foam models are as good as studies carried out on cadaveric models. Presently, density contributed the most to pull-out strength in both the single screw and two screw-rod configurations. Pull-out strength increased with increasing density in both testing configurations. These results are consistent with the values obtained in studies carried out on cadaveric and synthetic bone models $[15,16,22,23]$. In the present two screw and rod construct, bone density effect on holding power was significantly different when compared to single screw pull-out for all grades of bone densities. The increase in pull-out strength was not uniform across the bone densities. In case of extremely osteoporotic bone density $\left(80 \mathrm{~kg} / \mathrm{m}^{3}\right)$ it was highest at $78 \%$ and lowest for normal bone density $\left(240 \mathrm{~kg} / \mathrm{m}^{3}\right)$. This can partially explain the fewer number of clinical failures observed in vivo in osteoporotic bones, even though in vitro studies with single screw configuration predict higher failure. Further cadaver experiments need to be done to confirm this effect of instrumentation.

The effect of insertion angle on pull-out strength was significant based on ANOVA analysis $(p<0.05)$ in both configurations. This is the next important factor after bone density affecting screw pull-out. This factor represents the range of pedicle orientation in the lumbar region and its effect on the variation of pull-out strength. Pullout strength decreases with increase in angle for single screw configuration [24]. Similar results were presently observed using the single screw configuration. For this configuration, maximum pull-out was obtained at $10^{\circ}$ in osteoporotic bone $\left(80 \mathrm{~kg} / \mathrm{m}^{3}\right)$, whereas in normal bone the axial pull-out value was maximum. Patel et al. [21] reported that screws inserted with angles higher that $10^{\circ}$ are beneficial only in osteoporotic bone and not in healthy bone. In the present study, the maximum pullout strength for the two screw and rod configuration was obtained at an insertion angle of $10^{\circ}-15^{\circ}$ for osteoporotic bone. Thus, for good clinical results in osteoporotic bone there is a benefit of using insertion angle in the range of $10^{\circ}-15^{\circ}$. The percentage reduction in pull-out strength due to increase in screw angle predicted by single screw test configuration is considerably higher than the two screw test configuration for similar screw angles. This needs to be considered when extrapolating single screw test results for clinical predictions.

Reinsertion represents corrective surgery done by instrumenting pedicle screw of higher diameter $[11,25]$. In the single screw configuration, we observed an $18 \%$ decrease in the holding power when a higher diameter pedicle screw was used after the failure of instrumenta- 
tion which can happen per operatively or during revision surgery. However, with the two screw rod construct, the decrease was only $5 \%$. This is consistent with the observation of a in vivo study [26] that using a larger diameter screw may be sufficient in case revisions.

The results of the present study suggest that the interaction effect caused due to presence of the two screw and rod construct-the typical in vivo fusion construct -is significant and that bone density, reinsertion and screw insertion angle effect the pull-out force to various strengths in single and two screw constructs. The results obtained with the single screw construct should thus be carefully extrapolated for clinical use, particularly with osteoporotic bone and during revision surgery. The present study demonstrated statistically significant differences in the factor effects in single and two screw constructs in synthetic bone models. These results could be further verified with cadaveric models that better mimic the in vivo situation. Since biological samples have large intraand inter-sample variability, a similar study would require large sample size. In the present study, cyclic loading was not considered, since pull-out strength is more representative of holding power and also allows better comparison with other studies. Effect of screw geometry on the pullout phenomenon in both the configuration is another area needing further study.

\section{Conclusions}

The present assessment of the effects of density, insertion angle and reinsertion on pull-out strength of pedicle screw in single screw and two screw configurations demonstrated statistically significant differences between these factor effects in single and two screw constructs in synthetic bone models. The percentage increase in pullout strength between single and two screw constructs was higher for osteoporotic bone compared to normal bone. Pull-out strength was highest at an insertion angle of $0^{\circ}$ for normal bone density in single screw configuration, and was highest at a $10^{\circ}-15^{\circ}$ insertion angle in osteoporotic bone for two screw configuration. Reinsertion had no significant effect on pull-out strength in two screw configuration, whereas it showed significant reduction in the single screw pull-out test. The results suggest that the two screw constructs predict screw stability better for clinical use, particularly with osteoporotic bone.

\section{Conflict of Interest}

No potential conflict of interest relevant to this article was reported.

\section{References}

1. Sterba W, Kim DG, Fyhrie DP, Yeni YN, Vaidya R. Biomechanical analysis of differing pedicle screw insertion angles. Clin Biomech (Bristol, Avon) 2007; 22:385-91.

2. Chen CS, Chen WJ, Cheng CK, Jao SH, Chueh SC, Wang CC. Failure analysis of broken pedicle screws on spinal instrumentation. Med Eng Phys 2005;27: 487-96.

3. Gaines RW Jr. The use of pedicle-screw internal fixation for the operative treatment of spinal disorders. J Bone Joint Surg Am 2000;82:1458-76.

4. Hsu CC, Chao CK, Wang JL, Hou SM, Tsai YT, Lin J. Increase of pullout strength of spinal pedicle screws with conical core: biomechanical tests and finite element analyses. J Orthop Res 2005;23:788-94.

5. Amaritsakul Y, Chao CK, Lin J. Comparison study of the pullout strength of conventional spinal pedicle screws and a novel design in full and backed-out insertions using mechanical tests. Proc Inst Mech Eng H 2014;228:250-7.

6. Hu SS. Internal fixation in the osteoporotic spine. Spine (Phila Pa 1976) 1997;22(24 Suppl):43S-48S.

7. Okuda S, Miyauchi A, Oda T, Haku T, Yamamoto T, Iwasaki M. Surgical complications of posterior lumbar interbody fusion with total facetectomy in 251 patients. J Neurosurg Spine 2006;4:304-9.

8. Chapman JR, Harrington RM, Lee KM, Anderson PA, Tencer AF, Kowalski D. Factors affecting the pullout strength of cancellous bone screws. J Biomech Eng 1996;118:391-8.

9. Kwok AW, Finkelstein JA, Woodside T, Hearn TC, Hu RW. Insertional torque and pull-out strengths of conical and cylindrical pedicle screws in cadaveric bone. Spine (Phila Pa 1976) 1996;21:2429-34.

10. Lee WT, Koak JY, Lim YJ, Kim SK, Kwon HB, Kim MJ. Stress shielding and fatigue limits of poly-etherether-ketone dental implants. J Biomed Mater Res B Appl Biomater 2012;100:1044-52.

11. Fujibayashi S, Takemoto M, Neo M, Matsuda S. Strategy for salvage pedicle screw placement: a technical 
note. Int J Spine Surg 2013;7:e67-71.

12. Santoni BG, Hynes RA, McGilvray KC, et al. Cortical bone trajectory for lumbar pedicle screws. Spine J 2009;9:366-73.

13. Chao CK, Hsu CC, Wang JL, Lin J. Increasing bending strength and pullout strength in conical pedicle screws: biomechanical tests and finite element analyses. J Spinal Disord Tech 2008;21:130-8.

14. Hsu CC, Wang JL, Hou SM, Chao CK, Lin J. Pushout strength of tibial locking screws: development of finite element models. J Taiwan Inst Chem Eng 2003; 26:817-23.

15. Kim YY, Choi WS, Rhyu KW. Assessment of pedicle screw pullout strength based on various screw designs and bone densities-an ex vivo biomechanical study. Spine J 2012;12:164-8.

16. Chao KH, Lai YS, Chen WC, et al. Biomechanical analysis of different types of pedicle screw augmentation: a cadaveric and synthetic bone sample study of instrumented vertebral specimens. Med Eng Phys 2013;35:1506-12.

17. ASTM F1839-97. Standard specification for rigid polyurethane foam for use as a standard material for testing orthopaedic devices and instruments. West Conshohocken, PA: ASTM International; 2001.

18. Montgomery DC. Design and analysis of experiments. Estados Unidos: John Wiley \& Sons; 2006.

19. Mitra SR, Datir SP, Jadhav SO. Morphometric study of the lumbar pedicle in the Indian population as related to pedicular screw fixation. Spine (Phila Pa 1976) 2002;27:453-9.

20. ASTM F543-02. Standard specification and test methods for metallic medical bone screws. West Conshohocken, PA: ASTM International; 2002.

21. Patel PS, Shepherd DE, Hukins DW. The effect of screw insertion angle and thread type on the pullout strength of bone screws in normal and osteoporotic cancellous bone models. Med Eng Phys 2010;32:8228.

22. Inceoglu S, Ferrara L, McLain RF. Pedicle screw fixation strength: pullout versus insertional torque. Spine J 2004;4:513-8.

23. Ponnusamy KE, Iyer S, Gupta G, Khanna AJ. Instrumentation of the osteoporotic spine: biomechanical and clinical considerations. Spine J 2011;11:54-63.

24. Lehman RA Jr, Polly DW Jr, Kuklo TR, Cunningham B, Kirk KL, Belmont PJ Jr. Straight-forward versus anatomic trajectory technique of thoracic pedicle screw fixation: a biomechanical analysis. Spine (Phila Pa 1976) 2003;28:2058-65.

25. Polly DW Jr, Orchowski JR, Ellenbogen RG. Revision pedicle screws. Bigger, longer shims--what is best? Spine (Phila Pa 1976) 1998;23:1374-9.

26. Kang DG, Lehman RA Jr, Wagner SC, et al. Pedicle screw reinsertion using previous pilot hole and trajectory does not reduce fixation strength. Spine (Phila Pa 1976) 2014;39:1640-7. 